\title{
Typology of Implicature Questions in TOEFL-Like and Causes of Failure According to Gender
}

\author{
Hasan Arifuddin \\ Language Education University of Mataram, Lombok, Indonesia \\ E-mail: arifpgn@yahoo.com
}

Susanto Susanto

Language Education State University of Surabaya, Surabaya, Indonesia

E-mail: susantoniki@yahoo.com

Suharsono Suharsono

Language Education State University of Surabaya, Surabaya, Indonesia

E-mail: kangharsono@gmail.com

Received: September 17, 2013 Accepted: Oct. 21, 2013 Published: December 8, 2013

doi:10.5296/ijl.v5i6.4289 URL: http://dx.doi.org/10.5296/ijl.v5i6.4289

\begin{abstract}
Since women tend to use indirect speech, it is assumed that women face different causes of failure in each type of implicature question when doing Part A Listening Comprehension of TOEFL-like. The present study aims at exploring the: 1) types of implicature question that male test-takers failed to answer and the causes of failure and 2) types of implicature question that female test-takers failed to answer and the causes of failure. This case study involved six students of English Education Program University of Mataram selected based on the result of the preliminary study. Data were collected with tests, retrospective report, inventory of causes of failure, interview, recording and human instrument. Data were analyzed with Mixed Methods: Embeded Design. It shows that types of implicature questions that male and female test-takers' failed to answer are similar, except Predictable action question. However, some causes of failure to answer certain implicature questions are different. Detailed findings are shown.
\end{abstract}

Keywords: Typology, Implicature, TOEFL-like, Gender, Causes of failure 


\section{Introduction}

Arifuddin and Susanto (2012) express that inferring conversational implicatures could be difficult for foreign language learners. Such a difficulty leads to English language proficiency. English language proficiency is frequently tested with an instrument called Test of English as a Foreign Language (henceforth TOEFL. Saukah (2000) found that the mean TOEFL scores of English language lecturers in Indonesia is only 390.50. Among the three sections, Listening section is the most difficult one. This finding is consistent with the one reported by ETS (1997). Based on the data summary, means scores of Listening section, Structure and Written Expression and Reading Comprehension are 63.7, 69.7 and 69.1 respectively. It is probable that one of the causes of low total English proficiency could be low ability in implicature inference from short conversations. Blight (2002) states that understanding implicatures is still problematic for EFL learners and it hinders proficiency.

Language proficiency is inseparable from the users' gender. ETS test and score data summaries January 2011-December 2011 (ETS, 2012) and January 2008-December 2008 (ETS Researcher, 2008) report the mean scores and standard deviations of each section (or skill) according to 'gender' are different. Superficially, the mean scores of male and female test-takers look relatively similar. It indicates that TOEFL is gender-free. However, all standard deviations of males' mean scores are higher than those of females. Almost every year ETS reports the means scores of male and female test-takers. It implies that ETS realizes that gender potentially affects test-takers' TOEFL scores. The ETS's concern with the role of gender in English proficiency is a reasonable basis for investigating whether the types and intensity of causes of failure in inferring implicature from Part A of Listening section of TOEFL-like rely on test-takers' gender.

The difference of mean scores of implicature comprehension of males and females may be related to their preference in language use. It is found that females are prone to produce indirect speech and males direct speech acts in their verbal communication (Mckelvie, 2000; Mulac, Bradac, and Gibbons, 2001). Thijittang and Le (2009) suggest that more research on pragmatics need to be done. A limited number of research findings are reported. For example, it proved that gender influences aural pragmatic understanding (Amin, 2003; Cedar, 2006; Dykstra, 2006; Cohen, 2012) or implicature inference (Barati and Biria, 2011; Cocco and Ervas, 2012). More specifically, women outperformed men in answering inferential comprehension question of aural proficiency tests (John et al., 2003; Farashayian and Hua, 2012). However, none of the studies explored the types and causes of failure in inferring implicature from short conversations of TOEFL-like according to gender. This is the novelty of the study.

In relation to pragmatic failure, the problem is whether male and female test-takers experience different types of causes of failure in each type of implicature question when doing Part A Listening Comprehension of TOEFL-like. Research questions: 1) What types of implicature question do male test-takers fail to answer? 2) Why do male test-takers fail to answer implicature questions? 3) What types of implicature question do female test-takers fail to answer? 4) Why do female test-takers fail to answer implicature questions? 


\section{MIN Macrothink}

International Journal of Linguistics

ISSN 1948-5425

2013, Vol. 5, No. 6

Accordingly, the present study aims at exploring the: 1) types of implicature question that male test-takers fail to answer and the causes of failure under each type of implicature question and 2) types of implicature question that female test-takers fail to answer and the causes of failure under each type of implicature question.

\section{Methods}

\subsection{Participants}

This case study involved six students of English Education Program University of Mataram selected based on the result of the test in the preliminary study.

\subsection{Instruments}

Data about causes of failure to infer implicature were collected with tests (Part A TOEFL-like), retrospective report, inventory of causes of failure, interview, recording and human instrument.

\subsection{Procedures}

The present study was conducted according to the following phases: a) Preliminary studies; b) Subject selection using Part A Listening TOEFL-like; c) Data Collection; d) Data Analysis; and e) Verification of the findings. Note that the identification and categorisation of causes of failure and causes of failure employed Miller's (2001) and Goldkuhl's (2004) Typology of Implicature and Brown and Yule's (1983) and Rubin's (1994). Data were analysed with Mixed Methods: Embeded Design. Qualitative analysis was done using Yin’s (2011) iterative qualitative analysis integrated with Descriptive Quantitative: Frequency.

\section{Result and Discussion}

For the sake of clarity, the sample of test items and the responses expressed through interview and Inventory of Causes of Failure are coded as Test ..., Inter... and Invent... respectively. To avoid repetition, the same test items or excerpts are not repetitiously presented. The next test item(s) or excerpt(s) only refer(s) to the first one.

\subsection{Result}

As the bases for the description, explanation and discussion of the results, the types of implicature questions failed to be answered and the causes of failure are firstly presented. Based on their frequencies, the types of implicature question that male test-takers failed to answer involve Meaning, Inference, Reference, Deixis and Presupposition; while female test-takers failed in Meaning, Inference, Reference, Deixis, Presupposition and Predictable action questions The causes of failure to infer implicatures from Part A Listening section of TOEFL-like that male test-takers and female test-takers experienced are displayed in the following Chart. 


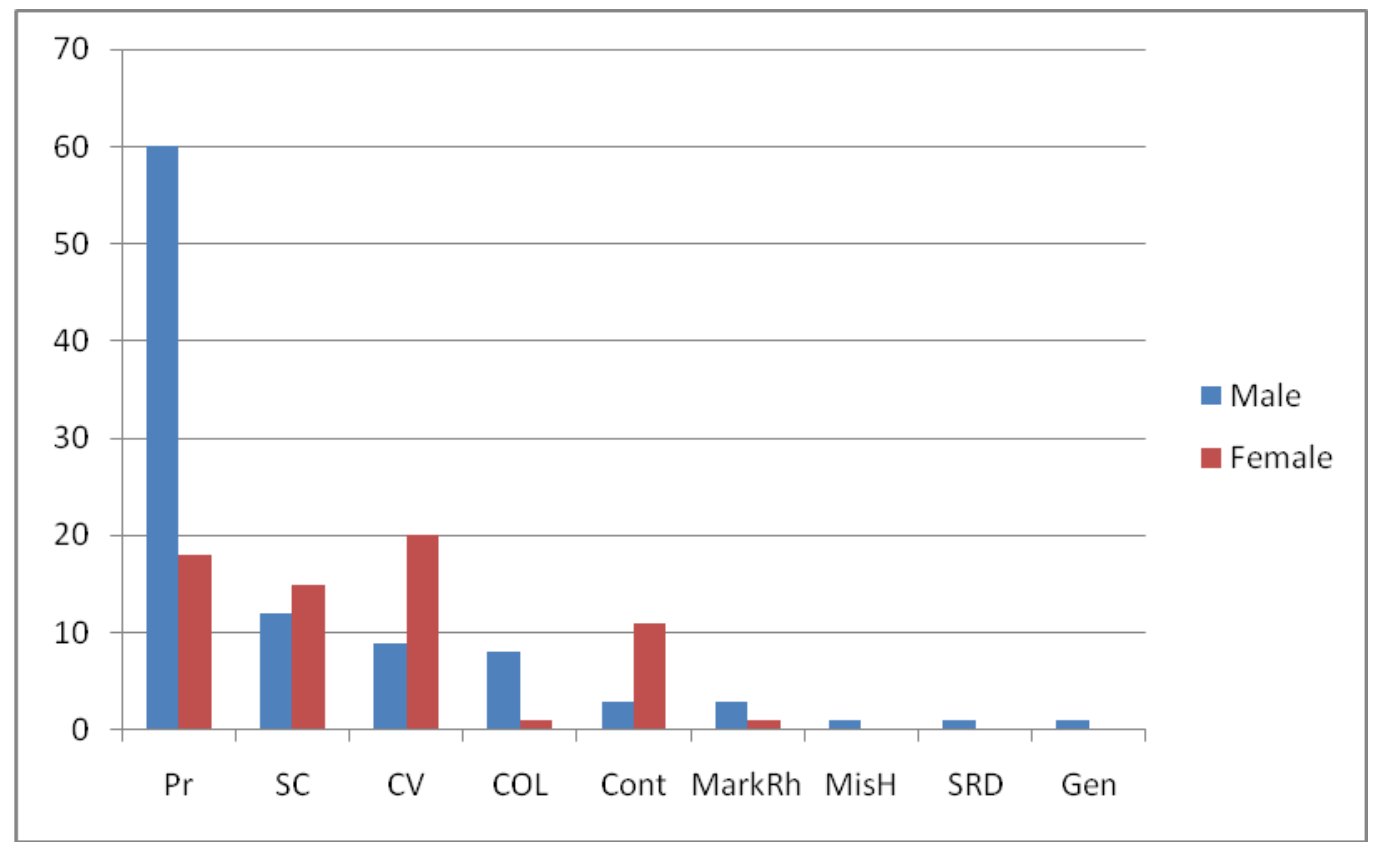

Figure 1. Male and Female Test-takers’ Causes of Failure

The order of nine causes of failure of male test-takers based on their frequencies: 1) Pronunciation (60), 2) Sentence Complexity (12), 3) Cultural Value (9), 4) Colloquial (4), 5) Context (3), 6) Discourse Marker (3), 7) Mishearing (1), 8) Speech Rate/Delivery (1), and 9) Gender (1). Pronunciation has been the most determinant factor which influences males' success in inferring conversational implicature. Three lowest levels of causes of failure Mishearing, Speech Rate/Delivery and Gender all are experienced by male test-takers. Meanwhile, the order of causes of failure of female test-takers: 1) Cultural Value (20), 2) Pronunciation (18), 3) Sentence Complexity (15), 4) Context (11) 5) Colloquial (1), 6) Discourse Marker (1). Despite its level, gender proved to be one of the causes of failure in inferring implicatures from short conversations in TOEFL-like.

\subsubsection{Types of Implicature Question and Male Test-takers’ Causes of Failure}

The categorization of implicature questions refers to the typology of implicature questions. Based on the identification, male test-takers failed to answer five types of implicature question: 1) Meaning/Intent question, 2) Inference question, 3) Reference question, 4) Deixis question and 5) Presupposition question. Their failure results from a variety of causes with their specific features. Further detailed description and analysis of each type of implicature question are as follows.

\subsubsection{Meaning/Intent Question}

Meaning/Intent question asks 'speaker's meaning', e.g. What does the man mean? Based on the identification of types of implicature questions tested in Part A of TOEFL-like, Meaning/Intent question is most frequently tested item, 47 percent of the total of 30 test items. And based on their frequencies, the causes of failure in Meaning/Intent question are categorized into three levels: (1) High: Pronunciation (28), (2) Medium: Sentence 
Complexity (8) and Cultural Value (6) and (3) Low: Colloquial (1); Mishearing (1) and Speed Rate/Delivery (1). Regarding the causes of failure, Pronunciation is the most dominant cause of failure. The description of each cause of failure in Meaning/Intent question that male test-takers experienced are as follows.

a) Pronunciation

Pronunciation as one cause of failure to understand implicature involves chunking the continuous stream of sound, voice, intonation and accent.

Based on the test-takers' experience when taking the listening test, one of the causes of failure to infer implicatures is their inability to chunk the connected sounds.

(Invent 1) "Rarely hear blended sounds and practise chunking in classroom.”

Based on Invent 1 above, he is not familiar with the way native speakers blend the neighbouring sounds when speaking.

Undoubtedly, clarity of speaker's voice (Voice) influences listener's understanding. One example is as follows.

(Test 1) Woman $\quad:$ How’s Linda's report card this semester?
Man
Narrator

The conversation in Test 1 above contains some words recognised as homophones. For example, the English words no and know are both pronounced /nəu/ in some varieties of British English.

The test-taker found that this item is hard because the he is confused with the meaning of words with similar sound or pronunciation. He said, "It is very hard to distinguish similar voices/minimal pairs." In the conversation, there is a word 'card'. The confusion is due to sound similarity. He was confused with the minimal pairs whether the word is 'car', 'cart', 'chart', 'guard', and the like.

Accent as an aspect of sound may make listening activity failed. For example, in English the noun 'import has the accent on the first syllable im- while the verb im'port has the accent on the second syllable -'port. Below is the sample of test item that male test-takers answered incorrectly due to unfamiliarity with accent.

(Test 2) Man $\quad$ : On Monday Betty starts with the tool company.

Woman : I am surprised she changed her mind about not taking that job.

Narrator : What does the woman mean?

He heard sir, 'priced changed her. Perhaps, he is accustomed to hearing Indonesian English 
pronunciation surprised with flat intonation.

(Invent 2) "The accent makes it difficult."

In relation to Test 2, it is hard to determine which words or phrases representing an accent that the test-taker is unfamiliar.

b) Cultural Value

Cultural values represent explicitly or implicitly shared abstract ideas about what is good, right and desirable in a society. Below is an example.

(Test 3) Man : : A lot of my friends are out of work, and they don't seem to be able to get any job at at all.

Woman : In the past few years, unemployment has been climbing dramatically.

Narrator : What does the woman mean?

The failure is due to lack of socio-cultural or socio-linguistic understanding. He interpreted out of work as going home after working hours.

The cause of pragmatic failure also relates to language habit.

(Invent 3) “Don’t know much cultural values, for example, 'assertiveness””.

Understanding the underlying values from certain terms in a conversation is difficult because different cultures tend to yield different interpretation. They admitted that intonation tends to imply cultural values. They claim that intonation is an observable indicator of cultural determinant in understanding pragmatic meaning. They talked much about cultural aspects in language use and in politeness, but they can not mention even a specific one, except intonation or please.

(Inter 1) Investigator : Did you find any markers of politeness or other language functions like criticism or heroism as we have just talked?

Subject 03 : May be from intonation, all from intonation. A high (rising) intonation may indicate anger or falling intonation as the indicator of politeness. I think so.

Cultural understanding was not explicitly taught.

(Invent 4) "Cultural values are not taught much.”

Although they have attended the course called 'CCU' and learned many things about western culture, they do not have sufficient understanding of western cultural values. What they have got from formal instruction has not been satisfying.

c) Sentence Complexity 
Sentence complexity refers to sentence types, such as simple sentences or long, complex ones with embeded clauses. One sample of incorrectly answered test items which are caused by sentence complexity is as follows.

$$
\begin{aligned}
& \text { (Test 4) Man } \quad \begin{array}{l}
\text { I didn't know you come here to shop. Are you thinking } \\
\text { of doing a little work on the house? }
\end{array} \\
& \text { S } \quad \text { Woman } \quad \text { My brother suggested that we buy a set of tools for our } \\
& \text { father's birthday. }
\end{aligned}
$$

SSchema is important in identifying the topic, but it is not something to do with TOEFL-like. Hinkel (2005:15) emphasises that listening section of TOEFL does not require schema of any specific subject or topic.

In the Inventory of Causes of Failure, the subject noted that,

(Invent 5) "It is difficult to understand content of the long sentence."

The subjects experienced that a complex sentence is difficult to interpret because it needs meaning processing.

(Invent 6) "Because it needs grammatical understanding and meaning processing.”

The subject said that long sentences are difficult to be processed.
(Inter 2) Investigator : ..., but perhaps it is important to tell me whether implicatures from conversations containing long sentences are easy or difficult to be interpreted.
Subject 04 : Understanding long sentences takes longer time, doesn't it?

Although they like reading Bola newspaper, novel and short story, listening to western songs, talking with native speakers and learning different cultures they still failed to derive speaker meaning or purpose from complex sentences. The other subjects experienced long sentences made them confused and tricky.

(Inter 3) Investigator : Then, in relation to the length of those sentences that you listened, are they difficult to be comprehended?

Subject 06 : If the sentences are too long, it is difficult to determine the point of speech. Usually, the narrator's utterances are tricky ....

\section{d) Speech Rate/Delivery}

Speech rate is the speed at which a person speaks. Fast speech rate/delivery can hurt listening comprehension, but slower speech rates do not necessarily help. The test item answered 
incorrectly due to speed rate/speed delivery is Test 1 . In the conversation, the first speaker uses at least two continuous sounds, e.g. how's and Linda's reports. The subject found that speakers, either the first or the second speaker or both, delivered the message too fast. He said that he did not get the content.

(Invent 7) "Don’t get the content, very fast.”

The researcher agrees that Test 1 is difficult. The difficulty is due to speed delivery and meaning. He does not understand the meaning of the phrase report card and and expression leave much to be desired.

Although in the interview they said that the majority of the test items are spoken in normal speed, they still made error in a certain item.

(Inter 4) Investigator : Next, what about the speed rate of the conversation?

Subject 02 : It's normal. If faster than it, may be we cannot answer the questions.

This subject heard all the words spoken by the interlocutors clearly, but he could not draw conclusion.

\section{e) Colloquial}

Colloquials are informal types of speech often marked by the use of slang or idioms and by other characteristics such as deletion of subject or auxiliaries (e.g. "Got the time?" instead of "Do you have the time?” ). The speaker uses a colloquial pick(ing) up. The test-taker did not understand the meaning of picking up.

(Invent 8) "I don’t have much vocabulary.”

Unfamiliar idioms or other colloquials hinder all test-takers’ understanding.

(Inter 5) Investigator : Next, how about your vocabulary mastery, primarily regarding idioms or idiomatic expressions. Does it affect your understanding of implicatures?

Subject 04 : Of course, idioms really influence our understanding.

In Inter 5 above, the use of idioms has been a burden for an EFL learner.

f) Mishearing

Mishearing is one of psychological states which may result from low concentration. The item answered incorrectly which is caused by mishearing is Test 5 .

(Test 5) Man : : You forgot to send a card to the Wilsons. 
Woman : I forgot! Why didn't you send one?

Narrator : What does the woman mean?

In Test 5 above, the speakers use relatively short sentences. They did not understand what the interlocutors meant, and even 'misheard.'

(Invent 9) "I missed the sound, not concentrated."

\subsubsection{Inference/Implication/Conclusion Question}

One example of inference question is 'What does the man (or woman) imply?'

(Test 6) Man : I'd like to take Math three-o-five (305) this semester.

Woman : To register for the course, students must have the instructor's permission.

Narrator : What does the woman imply?

Inference question is the most well-known type of implicature question.

Based on the frequency of the causes of failure, the causes of failure in Inference question are categorised into three levels: (1) High: Pronunciation (23), (2) Medium: Sentence Complexity (5), Colloquial (3); and (3) Low: Cultural Value (2) and Context (2). Surprisingly, context proved not to be the key factor which determines the success in inferring implicature asked with Inference question type.

Inference/Conclusion question is mostly failed to be answered by male test-takers. The causes of their failure are discussed one by one below.

a) Pronunciation

Clear pronunciation is very important in listening comprehension.

(Test 7) Woman : Benjamin looks different somehow. Have you noticed?

Man : Since he broke his glasses, he’s had to use a spare pair.

Narrator : What does the man say about Benjamin?

In Test 7, at least one contraction he's and one phrase spare pair are used. These two forms are difficult for the test-takers. He said that the cause of failure is 'similar voice'.

(Inter 6) Investigator : ... Does the presence of intonation, pause or stress uncommonly used in our language help you understand the dialogues?.

Subject $04 \quad$ : Yes ... yes ... yes, certainly, if stress, intonation or accent appears, I think it is facilitating.

He still finds difficulty in discriminating similar sounds.

The cause of failure due to the unfamiliarity with the speaker's accent was experienced 
when doing Test 7.

(Inter 7) Investigator : In a conversation, or listening in general, various intonation, pause, stress, or accent usually appear. Do they make you difficult to understand?

Subject 06 : Westerners are different from Indonesians. In Indonesian language, it is difficult to distinguish between instruction, anger, etc.

The failure to infer implicature from the following conversation (Test 8) results from inability to spare the individual words or sound from blended sounds.

(Test 8) Man : Are you looking for something to eat? There are apples and plums in the refrigerator.

Woman : I'm thirsty after having that salty hamburger for dinner.

Narrator : What does the woman imply?

He heard There apples send plams ... He missed the sound of are and was unable to segment apples and accurately.

(Invent 10) “Don’t understand reduced form.”

(Invent 11) “Confused with reduced form and voice.”

Slangs, idioms or other colloquials are not well-organised taught and used in EFL classrooms, so is connected sounds which require listeners' chunking. Other factor which affect listening comprehension is clarity of speaker's voice.

(Test 9) Man : Can I help you find something? You seem to be having a big trouble.

Woman : Do you have a stain remover that can take grease out of this shirt?

Narrator : What does the woman want to know?

In Test 9, the second speaker uses two expressions possibly new for the test-taker, for instance, stain remover and grease out. The subject found that sounds of some parts of the utterances in the dialogue are unclear, certainly on the part of the subject himself. He said that he,

(Invent 12) "Lacked of concentration and consequently did not recognize the native speakers’ voice.”

The second speaker's statement looks problematic for an inattentive listener. He just listened ... you have stand mover ..., instead of the complete one, "Do you have a stain remover that can take grease out of this shirt?”. Stain remover and grease are also faint for a listener with low concentration. 


\section{b) Sentence Complexity}

Test 8 one sample of incorrectly answered test items which is due to sentence complexity. He did not get the point, especially Man's speech Are you looking for something to eat? There are apples and plums in the refrigerator.

(Invent 13) "It takes long time to understand the content and grammar knowledge, so that it is difficult to know/get the point."

The subject said that a complex sentence is difficult to interpret.

c) Colloquial

One sample of the test items answered incorrectly which is due to the presence of idiomatic expressions, slang or colloquial is Test 8. Slangs, or the like need not be practised, but at least recognized.

(Invent 14) “I rarely practised/used unfamiliar with slangs, etc.”

It is an honest statement. The investigator is sure that Indonesian EFL learners rarely hear the expression I'm never home. He said, "I am doubt with never home. The expression I'm never at home is unfamiliar for some learners.

(Inter 8) Investigator : Do idiomatic expressions make the conversations difficult?

Subject $06 \quad$ : Yes, it is difficult because I have limited vocabulary.

Limited vocabulary inhibits his understanding.

d) Cultural Value

The inclusion of culturally specific vocabulary or constructions as found in Test 7 decreases listening comprehension.

(Invent 15) "Don’t know much vocabulary related to cultural values.”

In reality, learners of English encounter listening difficulties which could be due to lack of understanding of the pragmatic messages related to politeness.

(Inter 9) Investigator : In a conversation, sometimes there is an implied politeness. Is it not difficult to determine if the person is polite or not?”

Subject 06 : Certainly, sir.

Lack of understanding of politeness may result from limited exposures.

e) Context

Understanding speaker meaning relies on context of the exchange. 
10)

(Test Man : I am late for the presentation and can’t find the conference room.

Woman : Room four-o-seven (407) is not on the fourth floor but on the third.

Narrator : What does the woman imply?

In Test 10, the two speakers use compound sentences. He is unable to recognize the context of the speech.

(Invent 16) “Don’t know the context and never learned it.”

In Invent 16, the two speakers talk about a formal meeting. The attentive test-taker can easily recognize the key words, for instance, presentation and conference room.

(Inter 10) Investigator : Is it difficult to determine the context of a speech?” Subject $06 \quad$ : Honestly, it is difficult. It makes me confused.

Although schema activation is needed in conversational understanding, it is not required in inferring implicatures from TOEFL-like. That is specific feature of TOEFL, no prior knowledge or schema of specific topic or subject is required in order to be successful in taking TOEFL tests.

\subsubsection{Deixis Question}

Deixis deals with a word, phrase or situation which directly relates an utterance to a time, place or person(s). One example of Deixis question is Where does this conversation most probably take place?

$\begin{array}{ll}\text { (Test 11) Man } & : \text { How big a tip should we leave? } \\ \text { Woman } & : \text { Fifteen percent would be two dollars. } \\ \text { Narrator } & : \text { Where is the conversation taking place? }\end{array}$

He said, "I am uncertain with the setting." Based on the inventory, the primary causes of failure in Deixis question are: (1) Pronunciation and (2) Discourse Markers.

a) Pronunciation

The cause of failure in answering the test item is the inability to chunk the blended sound.

(Invent 17) "Difficult to understand blended sound."

The subject is not accustomed to hearing continuous stream of sound.

b) Discourse Marker

Discourse markers are words and phrases that signal the relationship between adjacent propositions and the overall structure of the passage. 
(Test 12) Man : : It's only three o'clock, and we've already sold all the paperbacks and half of the hardback editions.

Woman : Maybe we should have ordered more hardback copies.

Narrator : Where is the conversation taking place?

Although the only discourse marker found is and, the test-taker said that his failure was due to the presence of the discourse marker.

(Invent 18) "Confused the meaning of connector."

He said, "Many and (?) are used”. Certainly, in an aural sentence, simple thing may change into intricate one. The use of and recognized as a simple connector may lead to listener's confusion when used in an aural long sentence.

Below is a sample of interview dealing with the understanding of discourse markers.

(Inter 11) Investigator : A conversation usually contains connectors or conjunctions which connect either between sentences or between paragraphs. If they appear, is it facilitating?

Subject 06 : Yes, it is. The use of connectors facilitates listeners to comprehend their sentences.

The subject was confused with the meaning of connector used in the conversation above.

\subsubsection{Presupposition/Assumption/Attitude/Tone Question}

Presupposition is what a speaker or writer assumes that a receiver of the message already knows. On example of presupposition question is What does the man say about Susan?

(Test 13) Woman : We had a great time. And so many people came!

Man : It was very nice of George to give me a party.

Narrator : What does the man say about George?

The order of each determining factor of failure based frequencies for presupposition question is Pronunciation (5), Cultural Value (1), Gender (1), Discourse Marker (1) and Sentence Complexity (1). These kinds of causes of failure are described below.

\section{a) Pronunciation}

One sample of the test item answered incorrectly due to inability to spare the blended sounds known as chunking is Test 16.

(Invent 19) "Language function contains difficult blended sounds."

He found the second speaker's statement It was very nice of George to give me a party is difficult to chunk. He said, "Second speaker's stc. difficult to chunk." He heard It is nice/of course to/meparty. 
b) Cultural Value

Test 14 was answered incorrectly due to unfamiliarity with cultural value.

(Test 14) Woman : Judy has given her notice to the manager, and she will be leaving the office in two weeks.

Man : She made the right decision. I know she can use the better salary.

Narrator : What can be said about Judy?

The conversation implies a cultural value different from Indonesians’ habits.

c) Gender

Speaker's gender determines listener's understanding of pragmatic meanings. Test 15 below proved that man's voice is easier to be understood.

(Test 15) Woman : We had a great time. And so many people came.

Man : It was very nice of George to give me a party.

Narrator : What does the man say about George?

(Invent 20) "Man’s voice is easier."

He said that Man's voice is easy to understand. The failure to infer implicatures from speaker with different gender is experienced by a male test-taker when answering Presupposition question. The cause of failure is Pronunciation (Voice) (e.g. Man's voice is easier to understand.). This statement is expressed by male test-taker.

d) Discourse Marker

The test item below was answered incorrectly because the subject was unable to understand the function of a discourse marker in the conversation.

(Invent 21) "Generally it is easy, but now it is difficult.

The only connector used in the conversation is and. And begins the sentence. In Indonesian, and is not used in the beginning of a sentence.

(Inter 12) Investigator : A conversation or discourse generally contains connectors or conjunctions. Does the use of connectors or conjunctions facilitate or impede understanding?

Subject 04 : Of course it facilitates understanding. It is more difficult when connectors are absent.

e) Sentence Complexity

One sample of the test items incorrectly answered due to sentence complexity is Test 8. 
Invent 22 below also relates to the same cause of failure.

(Invent 22) "It is difficult to understand long sentences."

The first speaker's sentence It was very nice of George to give me a party is so long that he does not understand the content or the point.

(Inter 13) Investigator : ... If long sentences are found, is it difficult to infer the implicatures in conversations?

Subject 04 : Probably it is difficult because we have to do a long process.

The subjects experienced that a complex sentence is difficult to interpret. It needs meaning processing and it takes longer time to understand.

\subsubsection{Reference/Identification Question}

Reference is the relationship between words and the things, actions, events and qualities they stand for. One example is Who is the man (or woman)?

(Test 16) Woman : Your super-unleaded grade is pretty expensive.

Man : I don't think it's more expensive than at other places.

Narrator : What is the man's occupation?

Test 16 contains the type of implicature question failed to be answered due to inability to identify reference.

\section{a) Pronunciation}

Test 16 above is also an example of test item answered incorrectly due to inability to discriminate sounds. The subject made mistake because he is unable to understand the message expressed with continuous stream of sound.

(Invent 23) “It is not clear, the sounds combined."

He was unable to chunk Your super-unleaded grade is pretty expensive accurately. Unfamiliarity with speakers' blended sounds makes him failed.

\section{b) Context}

The difficulty of the conversation presented in this part is related to its implied context (see Test 16). Although context facilitates listeners, in this conversation it proves that the presence of many contexts is misleading.

\subsubsection{Types of Implicature Question and Female Test-takers' Causes of Failure}

Based on their frequencies, the types of implicature questions failed to be answered by female test-takers are: (1) Meaning/Intent question (22), (2) Inference/Conclusion question (13), (3) (4) Presupposition/Assumption/Tone question (7), (5) Deixis question (6), 
Reference/Identification question and (6) Predictable Action question (1).

\subsubsection{Meaning/Intent Question}

The causes of failure are categorized into three levels, namely: (1) High: Pronunciation (11) and Cultural Value (7), (2) Medium: Sentence Complexity (6) and Context (5) and (3) Low: Colloquial (1) and Discourse Marker (1).

Female test-takers' perception about the causes of their failure to infer implicatures in the second test, their failure to infer implicatures from short conversations in this type of implicature question are Pronunciation, Cultural Value, Sentence Complexity, Context, Colloquial and Discourse Marker.

\section{a) Pronunciation}

The aspect of pronunciation which made the subejct failed is accent.

(Test 17) Man $\quad$ : Did Doug go with you to the precinct?
Woman $\quad:$ Doug isn't old enough to vote.
Narrator $\quad:$ What does the woman mean?

The subject does not recognize the speakers' accent. She heard Though is an old enough to vote instead of Doug isn't old enough to vote. The heard idea is extremely contradictory with the original sentence. Native speakers tend to use reduced forms, for instance, isn't instead of is not.

(Invent 24) “Accent may cause misunderstanding, I do not recognize many accents.”

Her unfamiliarity with paralinguistic features of spoken language that she heard from the conversation leads to her failure in inferring the implicature.

Test 18 is presented as an example of the subject's failure to grasp the idea from the continuous stream of sounds in the following conversation.

$\begin{array}{lll}\text { (Test 18) Man } & : \text { Do you have blank cards? } \\ \text { Woman } & : \text { Pharmacies seldom carry stationery. } \\ \text { Narrator } & : \text { What does the woman mean? }\end{array}$

(Invent 25) "Seldom listen to reduced forms."

She said that she did not understand blank arts. The phrase blank cards is one example of blended or connected sounds.

b) Cultural Value

One example of the test item answered incorrectly due to lack of understanding of cultural values is Test 19 .

(Test 19) Woman : The phone company called this morning, and there appears to be a problem. 
Man : This is the second time Peter forgot to pay it.

Narrator : What does the man mean?

The conversation talks about paying bill. She is unfamiliar with the western culture.

(Invent 26) "Unfamiliar with cultural values”.

She does not have background knowledge dealing with how the consumers of public telephone in western countries pay the bill. She said, "I don't know how to pay the bill." Native speakers of English have different ways of expressing their cultural values from Indonesians do (See Inter 10).

(Invent 27) “Cultural values rarely taught formally, only introduced in CCU.”

Similar statement is also expressed in Invent 3. They lack of cultural values. Another factor which cause pragmatic failure is the presence of irony.

(Inter 14) Investigator : $\quad$ Is it difficult to distinguish language functions, e.g. suggestion, request, complaint, etc?

Subject 01 : That is the problem. The topic of conversation with complex sentences is tricky and distracting. ...

The subject experienced that intonation is a determinant factor for understanding an irony.

c) Context

The test answered incorrectly due to the difficulty in identifying the context is Test 19 . Based on her statement below, any contexts should be recognized.

(Invent 28) "Different concept of context."

Context has been the focus of listening comprehension.

d) Sentence Complexity

Test 20 was answered incorrectly due to sentence complexity.

(Test 20) Man : : I didn't know you come here to shop. Are you thinking of doing a little work on the house?

Woman : My brother suggested that we buy a set of tools for our father's birthday.

Narrator : What does the man mean?

The two speakers use too long sentences. This makes the conversation difficult to interpret.

(Invent 29) "It is difficult to get the point of long sentences.”

Since the two speakers use so long sentences, the test-taker answered the question incorrectly. Even the first speaker uses two sentences at the same time.

(Inter 15) Investigator : Related to sentence complexity, does it affect your 
understanding of conversations?

Subject 01 : That is the problem. The topic is tricky and distracting.

It takes long time to comprehend long sentences. Besides, understanding long sentences needs high concentration.

(Invent 30) "Can’t focus on the content because it needs concentration and grammatical understanding."

e) Colloquial

The failure to comprehend an aural text or discourse in Test 1 is often caused by limited vocabulary, particularly idioms or slangs. She said that she did not understand the meaning of the rest of the sentence spoken by the second speaker much to be desired. This is a rarely heard colloquial, so that she misinterpreted the utterance.

(Inter 16) Investigator : How about vocabulary?.

Subject 01 : Yes, that is one of the difficulties in listening. If we don't recognize vocabulary, we do not understand the theme, and certainly it is much complicated if the vocabulary are the key words.

Limited vocabulary affect listeners' understanding of theme of a conversation. One of the subjects said that her vocabulary size is small.

(Invent 31) "Limited vocabulary.”

If the listeners do not recognize certain key vocabulary, when listening in particular, they may lose the meanings of conversations or spoken exchanges.

f) Discourse Marker

Test 2 was answered incorrectly due to the emergence of discourse markers.

(Invent 32) "Difficult to understand discourse markers."

It looks contrary to her general impression. In the interview she said that discourse markers often help her understand the message in a conversation.

(Inter 17) Investigator : Is it difficult to understand the discourse markers used in the conversation?

Subject 05 : If two sentences are connected with a connector, it is easy to understand.

One function of a discourse marker is to make the relation of sub-ideas or sentences coherent or to signal the discourse structure of a passage.

\subsubsection{Inference/Implication/Conclusion Question}

Based on their frequencies, the causes of failure are categorized into three levels: (1) High: 


\section{Macrothink}

International Journal of Linguistics

ISSN 1948-5425

2013, Vol. 5, No. 6

Cultural Value (7), (2) Medium: Sentence Complexity (5); and (3) Low: Pronunciation (4) and Context (3). Surprisingly, Pronunciation changes. Its position is in the medium level, instead of as the 'top one'.

The causes of their failure to infer implicatures from short conversations asked with Inference question are described as follows.

a) Cultural Value

One example of the test items answered incorrectly due to lack of cultural knowledge is shown in Test 21 below.

(Test 21) Woman : Today, I had a lot to do, with all the little things to take care of.

Man : You dropped off my jacket at the cleaner's, didn't you?

Narrator : What does the man want to know?

The failure to infer implicature is due to low understanding of the 'cultural values' and their indicators. Today, I had a lot to do, with all the little things to take care of contains two contrary ideas.

In the Inventory of Causes of Failure, one of the subjects wrote:

(Invent 33) " "Rarely studied and practised cultural values.”

The only indicator of cultural value underlying a conversation that the subjects recognize is intonation.

\section{g) Sentence Complexity}

One of the test items answered incorrectly due to the complexity of the sentence(s) is Test 21. It is difficult to infer implicatures or draw conclusion from dialogues with long, complex sentences.

(Inter 18) Investigator : Are complex sentences difficult to be understood?

Subject 02 : Yes, it is difficult sir. ... It takes long time to draw conclusion.

The subject said that it is difficult to draw a conclusion from long sentences. Because it takes long time to comprehend long sentences, it is difficult to get the content of the long sentence in limited time as allocated in TOEFL-like.

h) Context

One sample of the test items answered incorrectly due to the complexity of the sentence(s) is as follows.

(Test 22) Woman : Christie said you didn’t have enough chairs last night. 
Man : We didn’t expect forty people to attend the workshop.

Narrator : What does the woman imply?

The cause of failure in inferring implicature from the conversation is lack of exposure and direct interaction with native speakers.

(Invent 34) "Lack of exposure and contact."

For foreign language learners, limited exposure to the foreign language situations inhibits the improvement pragmatic competence. On one hand, it is difficult to identify the context of a conversation. On the other hand, context may also be the clue of the answer.

(Inter 19) Investigator : Does the context of the conversation facilitate you to answer the question?

Subject $02 \quad$ : Mm ... in my mind, yes//, it depends, sir.

It indicates that context may or may not facilitate listeners to understand the meaning of a conversation.

\section{i) Pronunciation}

Pronunciation also covers the use of blended sounds. The subject did not hear a clear message from the conversation. This results from her weakness in anticipating the emergence of blended sounds. Test 8 contains such a cause.

Lack of exposure potentially contributes to the low listening ability.

(Invent 35) "Rarely used and listened to blended sounds."

She admitted that she rarely used and listened to blended sounds and reduced forms. Besides, she is not accustomed to chunking.

\subsubsection{Deixis Question}

The causes of failure are categorized only into two levels: (1) Medium: Pronunciation and Cultural Value, (2) Low: Sentence Complexity and Context. Pronunciation and Cultural Value have equivalent potencies to affect pragmatic understanding, so do Sentence Complexity and Context.

\section{a) Pronunciation}

The cause of failure experienced in Test 11 is due to inability to segment the blended sounds heard from the speakers. The difficulty in chunking is expressed in Invent 17. The test-taker could not chunk appropriately. In Test 11, she heard, ”... put in the kju comer seeds two?” It is really meaningless. 
b) Cultural Value

Lack of cultural understanding is the factor which made the test-taker failed to answer Test 23 below.

$$
\begin{array}{ll}
\text { (Test 23) Man } & : \text { How big a tip should we leave? } \\
\text { Woman } & : \text { Fifteen percent would be two dollars. } \\
\text { Narrator } & : \text { Where is the conversation taking place? }
\end{array}
$$

The conversation talks about leaving a tip and how much it should be given. The main causes of failure of the item above is related to cultural value.

(Invent 36) “Limited knowledge, only introduced in CCU.”

Based on the statement, even in culture-oriented subjects, e.g. Cross-cultural Understanding (CCU), cultural knowledge is not much introduced.

(Inter 20) Investigator : Is it not difficult to understand sentences implying politeness?

Subject 02 : Yes, it is difficult.

Ideally, they should also have got a variety of cultural understanding, especially cultural values.

c) Sentence Complexity

The test item answered incorrectly due to sentence complexity is Test 12 . The cause of failure is expressed in Invent 37 below.

(Invent 37) "Content of a complex sentence is difficult to understand."

She said that Man's sentence is too long and complicated. There are two ands used in the same sentence. It is very difficult to understand. In the interview she told the same thing. An aural complex sentence is difficult to comprehend.

(Inter 21) Investigator : Is it difficult to draw conclusion from a complex sentence?

Subject $02 \quad$ : Yes, it’s difficult sir, particularly long sentences.

d) Discourse Marker

(Invent 38) "Confused with the meaning of connector."

The majority of the subjects said that the presence of connectors do not impede inferring implicatures from conversations.

(Inter 22) Investigator : Is it difficult to understand a conversation containing a discourse marker?

Subject $05 \quad$ : It is easy to understand two sentences connected with connectors. 
The absence of discourse markers makes the test item difficult to infer.

e) Context

When she answered Test 23, she could not identify the context of the conversation. The inability to recognize the context results from unfamiliarity with context of plantation activities. Actually she knows tomato, but she cannot relate it with the other clues, for instance, plenty of space or seeds.

(Invent 39) "Rarely do conversation with foreigners.”

However, when asked if context facilitates understanding, she said that sometimes it could be a clue.

(Inter 23) Investigator : Does the context of the conversation facilitate you to answer the question?

Subject $02 \quad$ : Mm ..., yes, it depends ..., sir.

Context does not always facilitate listener to listen effectively. The subject honestly said, "Rarely do conversation with foreigners."

\subsubsection{Presupposition/Assumption/Attitude/Tone Question}

Based on their frequencies, the levels of the three causes of failure are: (1) High: Cultural Value (4), (2) Medium: Sentence Complexity (2) and (3) Low: Context (1). Only some sample items with certain causes are presented.

a) Cultural Value

In Test 14, given notice the manager and then leaving office and using the batter salary are uncommon in Indonesian culture. This culture-laden expressions have been the obstacle for her to infer Judy’s attitude.

\section{b) Sentence Complexity}

The example of item below was answered incorrectly because the subject could not recognize the topics of the complex, long sentences. The sentences are not really long, but the intricacy of structure makes them difficult (See Test 7).

(Invent 40) “It takes long time to recognize the topic/content of long/complex sentences.”

The length or complexity of the item makes her unable to identify the topics or types of language functions. The second speaker's statement Since he broke his glasses, he's had to use a spare pair is complicated. Her opinion is expressed in Inter 21.

\section{c) Context}

The following item was answered incorrectly because she did not accurately recognize the context of the dialogue. 


\section{Al Macrothink}

(Invent 46) "Limited exposure, do not know the context."

The subject is also familiar with context of Test 13. The subjects' failure to infer implicature from the short conversation resulting from unfamiliarity with context is expressed in Inter 23.

\subsubsection{Reference/Identification Question}

The factors (or causes) which make them failed to infer implicatures from short conversations with this type of implicature question are briefly described below.

\section{a) Sentence Complexity}

Conversation in Test 16 provides sufficient no clues to the listeners. The only clue is the word 'expensive'. She said that the sentences are so complex so that they are difficult to infer, inferring the topic in particular.

(Invent 41) "It is difficult to know the topic."

Sentence complexity is problematic.

(Inter 24) Investigator : Does complex sentences, embeded with some further clarifications, affect your understanding?

Subject $01 \quad$ : We were distracted when identifying their topics.

Interpreting the implicature of a conversation containing complex sentences is a hard job.

b) Pronunciation

Superficially, conversation in Test 21 contains sentences with 'normal' length. However, the second speaker using contracted forms or sounds. This way of pronouncing may lead to listening failure.

(Invent 42) “ It is difficult to chunk.”

Actually all of the subjects do not find problems with intonation.

(Inter 25) Investigator : Is it difficult if a native speaker uses diverse intonations or accents?

Subject $05 \quad$ : No, sir. Even it facilitates us.

Unfortunately, they are not good at understanding continuous sounds. Chunking as a listening strategy is still difficult to apply.

\subsubsection{Predictable Action Question}

Predictable action question measures the listeners' ability to anticipate or predict the most probable activity based on the utterances being heard. One example of Predictable action question is What is the man (or woman) probably going to do?

The predictable action question failed to be answered is as follows. 
Mll Macrothink

(Test 24) Man
: It's time to go home, Karen. Dave and I are on our way to an Italian restaurant on High Street. Would you like to come to dinner with us?

Woman : Thanks, but I have the travel report to finish. I need to mail it first thing tomorrow morning.

Narrator : What is Karen going to do?

The causes which make her failed in inferring implicatures from short conversations asked with this type of implicature question is context. She rarely talked with native speakers. She cannot predict the question to be asked quickly.

(Invent 43) “ Rarely talked with native speaker.”

She didn't understand the context because she was never involved in and exposed to travel business. For all subjects, when two or more conversations are asked with similar questions focusing on context, they perceived that it is difficult.

(Inter 26) Investigator : Is it not difficult to determine the context of different conversations asked with relatively the same questions?

Subject 05 : Oh, yes, it is. I don't understand, difficult.

Predicting is one of the sub-skills of listening comprehension. One example of inferencing activity is to predict the probable action. Regarding the types of questions answered incorrectly, only female test-takers answered 'Predictable action' question incorrectly. This failure is due to lack of understanding of Context (e.g. Rarely talked with native speaker).

Different from those of male test-takers, the top rank cause of female test-takers' failure is Cultural Value. The order based on frequencies is Cultural Value (20), Pronunciation (18), Sentence Complexity (15), Context (1), Discourse Marker (1) and Colloquial (1). Pronunciation and Sentence Complexity are also in the high position. Like male test-takers, female test-takers place Context in the medium level.

\subsection{Discussion}

According to the results, male test-takers experienced both similar and different causes of failure in inferring implicatures for each type of implicature question. A number of factors are required to infer implicatures asked with a certain type of implicature question.

\subsubsection{Meaning/Intent Question}

\section{a) Pronunciation}

Pronunciation is the most dominant cause of failure. Male test-takers are unable to segment the continuous sounds. As a kind of active listening, understanding similar sounds, e.g. minimal pairs, and accents is difficult for male test-takers. This finding is in line with Nissan 
et al.'s (1996:4) suggestion that in a communicative listening, the listener must be active. It is found that accents affect male the test-takers' listening ability. This is relevant to Richards and Schmidt's (2002:2) statement that one's accent or way of speaking may facilitate listeners to understand aural language and Butt et al.'s (2010) study which indicates that accent, pronunciation and colloquial expressions are found to be the major obstacles in the development of listening skills.

Although with lower frequency, female test-takers also found sounds of speech acts asked with Meaning/Intent question difficult to understand. The meaning of a speech act meaning may also be affected by the speakers' pronunciation or accent. In the present study, based on the frequencies of causes of failure related pronunciation, females outperformed males. This is relevant to Eisenstein's (1982) research finding which shows that females consistently and significantly outperformed males in discriminating among different American English accents.

In order to be familiar with foreign language sounds, a learner needs also to expose to the real situation of the language use. This finding is in line with Alagozlu and Buyukozturk' (2009) view that pragmatic-awareness raising may be done inside or outside of classroom. Pragmatic competence should be integrated in foreign language teaching, indoor and outdoor tasks.

b) Cultural Value

For male test-takers, cultural values should also be considered when a curriculum developer designs EFL syllabuses. Cross-cultural knowledge needs to be formally taught. This is in line with Corsetti's (2010) suggestion that the ability to recognise the unsaid and cultural references related to language use should be explicitly taught in EFL classroom. Broadly speaking, Rueda (2006) suggests that instruction in pragmatic skills and knowledge be carried out formally, as a part of regular content in second or foreign language curricula. Since the majority of pragmatic uses are practices in spoken language, pragmatics should be integrated in listening skill.

Most applied linguists suggest that listening skills could also be acquired through exposure, not only through formal instruction. Their recommendation is relevant to Alagozlu and Buyukozturk's (2009) and Dogancay-Aktua's (2005) suggestions that pragmatic competence should not only be taught, but also acquired through exposure. Lack of exposure to the foreign language environment hinders learners pragmatic awareness. This is also relevant to Barati and Biria (2011) study indicating that exposure, sex and age influence inferencing skill or pragmatic understanding. Currently, male test-takers have exposed to the foreign language environment, but their strategies have not been optimally effective. However, male test-takers experienced lower level of causes of failure in understanding cultural values.

Like male test-takers, female test-takers find difficulties in recognising cultural values in conversations. They do not have sufficient background knowledge dealing with western cultural values and pragmatic meaning in conversations. Although they have attended the course called 'CCU' and have learned many things about western culture, they do not have sufficient understanding of western cultural values. In order to raise learners’ pragmatic 
understanding, it is suggested to integrate cultural understanding with general English curriculum. This is in line with Corbett's (2003:33) belief that when culture is implicitly built into ELT courses, learners will automatically acquire cultural knowledge. Understanding culture could be difficult.

Lam (2007:248) found that understanding aural pragmatic meaning is difficult. The difficulty is due to lack of understanding of the pragmatic messages as an aspect of socio-cultural or socio-linguistic understanding. Substantially, socio-cultural values cannot be separated from language. This finding is relevant to Kramsch's (1993) view that every time we speak, we perform a cultural act or value, so that it is necessary that cultural knowledge be involved in language teaching/learning. Accordingly, every conversation in TOEFL-like contains at least a cultural value.

In relation to TOEFL-like, female test-takers find irony difficult to derive. Gender proved to determine listener's understanding of irony. Different genders show different ability in understanding irony. This is consistent with Cocco and Ervas's (2012) study which shows that gender differences have proved to determine the use and interpretation of irony and sarcasm.

With regard to preference, generally, women prefer to use indirect speech act, including irony. This assumption is relevant to Yate (2010) and Cocco and Ervas's (2012) study which show that women seem to both give and receive compliments more often, while men seem less often. Besides, the social function of irony are more employed by women than men. However, the fact is that female test-takers still find irony, as an example of speech acts, difficult to interpret. It means that their preference does not guarantee their success in understanding pragmatic meanings.

As mentioned earlier, background knowledge and proficiency which could be supported with related classroom tasks also support pragmatic competence. This is relevant to Lee's (2010) statement that low proficiency L2 learners are less competent in interpreting implied meaning than high proficiency L2 learners.

Undoubtedly, the use of language is so closely tied to cultural values, or value laden. Therefore, to raise EFL learners' cultural-awareness, English as an international language needs to be taught in a culturally sensitive manner. Jiwandono (2006) illustrates how important cultural understanding for the test-takers' accuracy in inferring implicature from a short conversation in Part A of TOEFL. According to Bloomfield et al. (2011:ii-iii), lack of familiarity with culture-related vocabulary leads to pragmatic failure. Therefore, idioms and culturally specific vocabulary in English conversations should be included in classroom tasks.

\section{c) Voice}

Voice determines listener's pragmatic understanding. Generally, understanding voice requires both cognitive, physical and psychological aspects. Psychological factors, such as concentration and attention are needed when working out implicatures. Inferring implicatures 
from complex sentences requires familiarity with culture-related vocabulary and context. EFL learners need to interact with English native speakers from different cultural and dialectal backgrounds. They should also be familiar with voice of standard and nonstandard language varieties.

Voice understanding might result from the way a certain gender produces speech sounds. Speaker-listener shared gender facilitates voice understanding. The ease of understanding the voice result from intense interaction of people with the same gender. The difference of patterns of language use between men and women may cause misunderstanding. This finding is relevant to Holmes's study in Itakura (2001:320) which indicates that women and men develop different patterns of language use. It means that the same gender interlocutors tend to easily understand each other.

\section{d) Sentence Complexity}

Identifying the topic of a short conversation is one of the main purposes of listening comprehension of TOEFL-like. The test taker experienced that understanding topics of long sentences requires schema. This is relevant to Widdowson's (2009:28) view that schema is important in making inference. However, this is contradictory with Hinkel's (2005) statement that schema is not required in TOEFL tests.

Generally, detecting topic of a long sentence is difficult. Kostin's (2004:3) study shows that in TOEFL, syntactic complexity affects listening comprehension such that the more complex the syntax is in a text, the more difficult it is to comprehend. In relation to gender, Boyle (1987) found that female students of Chinese university in Hong Kong achieved higher overall means on ten tests of general English proficiency and the differences were significant.

In the present study, female test-takers found no problem in understanding long, complex sentences. This finding is relevant to Labov's (1991:206) principle that men use a higher frequency of non-standard forms than women. Long, complex sentences are generally standard. It is also consistent with Zaidi's (2010) note which argues that women are better than men in interpreting the meaning of long sentences because they use both hemispheres simultaneously (or bilaterally).

\section{e) Speech Rate/Delivery}

That the ability to interpret speaker meaning is affected by 'speech rate' has been commonly expressed by EFL learners. This is relevant to Matsuoka's (2009) study which shows that talking speed of people in the conversations is one of the eight factors that made listening difficult, including TOEFL. In the present study, male test-takers found some conversations were spoken with high speech rate. As a result, they could not segment the blended sounds and missed the messages.

\section{f) Colloquial}

In order for a speech act to be appropriately inferred, the speaker should facilitate the hearer 
to recognise the vocabulary used in the utterances. This principle is relevant to Bara's (2010:137) suggestion that the actor must avoid using idiomatic forms of expression if she wishes the hearer to take her seriously. Thus, the speaker should consider when to use particular idiomatic expressions or colloquials.

The inclusion of pragmatic constructs such as idioms and culturally-specific vocabulary decreases comprehension. Accent, pronunciation and colloquial expressions are found to be the major obstacles in the development of listening skills among students (Butt et al., 2010). Male test-takers experienced that pronunciation is the most dominant cause of failure in inferring implicatures. This finding is in line with Larsen-Freeman and Long (1991) hypothesis that females may possess better listening skills than do males.

The importance of vocabulary in TOEFL short conversations is also reported by the ETS researchers. One of the five significant factors which make the dialogue items in TOEFL ${ }^{\circledR}$ Listening Comprehension difficult is the presence of infrequent oral vocabulary (Susan et.al., 1996). Arifuddin (2012) also agrees that as a requirement for language proficiency, vocabulary mastery has been one of the targets of language learning. Obviously, the key to language use is vocabulary mastery.

Female test-takers also found that their ability to infer implicatures from short conversation in TOEFL-like relies on their vocabulary mastery. Their experience is relevant to Treiman et al. (2003) view that comprehending aural language requires not only understanding the meanings of individual words, but also being sensitive to the use of figurative expressions, for instance, metaphor, irony or idiomatic expressions. Generally, daily conversations focus on the use figurative or idiomatic expressions. In other words, in every language, there are frequently-used figurative language, such as idioms and expressions, that allow its speakers to convey nuances of thought to one another effortlessly and with greater clarity that simply explain everything verbally.

\section{g) Mishearing}

Mishearing as one of pasychological states may result from, for instance, low concentration, memory or inattention. Male test-takers found some conversations were spoken with high speech rate which causes mishearing. They could not make a chunk the continuous stream of sounds due to low memory. However, female test-takers did not report such a problem. This is relevant to Lenarz et al.'s (2012) study showing that the advantage of language tasks in women can be due to a more efficient declarative (long-term) memory system. Therefore, concentration, attention, memory and other psychological factors supporting listening are required when people do listening comprehension tests.

\section{h) Context}

Meaning is inseparable from context. Principally, context determines what message a discourse or an exhange implies. In relation to understanding a discourse marker, only did female test-takers find Meaning/Intent question difficult. They lack of schema and context understanding. This finding is relevant to Loukusa's (2007) statement that context 
encompasses all information that the hearer utilises when interpreting language expressions. In inferring pragmatic meanings, listener connects utterances with the contexts, schema. However, it is irrelevant to Hinkel's (2005:15, 19, 31 and 33) statement emphasizing that schema is not needed in doing TOEFL.

\subsubsection{Inference/Implicature Question}

\section{a) Pronunciation}

Krashen (1982:318) notes that phonological difference between the speech of men and women have been reported from a variety of languages. In the present study, for male test-takers, the speaker's voice contributes to their understanding of implicatures implied in TOEFL-like short conversations. In relation to it, Black (2006:17) emphasizes that, substantially, the use of speech acts is usually accompanied by the context of utterances and paralinguistic features, such as, sound discrimination.

A speaker's accent is one of the common factors affecting EFL learners' listening comprehension. Lack of familiarity with the diverse accents affects listening comprehension. This is relevant to Butt et al.'s (2010) study which indicates that accent, pronunciation and colloquial expressions are the major obstacles in the development of listening skills.

Female test-takers also found that it was hard to infer implicatures from short conversations spoken with blended sounds, but it is not as extreme as male test-takers are. This finding is consistent with Larsen-Freeman and Long's (1991) hypothesis that females are superior to males in listening skills.

\section{b) Sentence Complexity}

As experienced when answering Meaning/Intent question, complex sentences in short conversations of TOEFL-like proved to be hard for male test-taker to understand. This finding is consistent with Garai and Scheinfeld's study in Markovic (2007) indicating that females surpass men in verbal fluency, correct language usage, sentence complexity, grammatical structure, spelling and articulation, while males tend to excel in verbal reasoning and comprehension.

\section{c) Colloquial}

Although, according to Labov (1991:206) and Romaine (2003), men use a higher level of frequency of non-standard forms of English than women, in the present study, male test-takers still found difficulties in understanding colloquials because they are not member of the speech community. This finding is relevant to Black's (2006:19) view that inferencing meaning in conversation might be appropriate if the interlocutors are members of the speech community. However, Hinkel (2005) emphasizes that schema is not required in doing TOEFL.

d) Cultural Value 
Lack of understanding of politeness may result from limited exposures. The subjects are unfamiliar with how male and female westerners express their politeness. The way men and women express their politeness is different. This is relevant to Bradley's Study in Itakura (2001:320) indicating that women use certain patterns associated with surprise and politeness more often than men.

\section{e) Context}

Both males and females their limited schema causes failure. This finding is relevant to Fernandez and Cairns's (2011:250) and Blume's (2010) statements that schema could be raised through practice.

\subsubsection{Deixis Question}

a) Pronunciation

For male test-takers, continuous stream of sound that the speakers used in the conversation hinders their understanding about the meaning related to the use of deixis. For females, the second speaker's utterance is difficult to interpret. This finding is relevant to Wright and Sukur's (2011:2) statement that the speaker meaning is usually based on the second speakers' utterances.

\section{b) Discourse Marker}

Both male and female test-takers said that the presence of discourse markers does not hinder understanding. This finding is relevant to common belief that the presence of discourse markers in a discourse facilitates comprehension. However, in the test, they failed in inferring implicatures related to discourse markers. To be good listeners, they should carefully identify and understand the function and meaning of discourse markers.

\section{c) Cultural Value}

Only female test-takers failed in inferring implicatures asked with Deixis question. The cause of failure is limited understanding of cultural value. They lack of direct interaction with native speakers and limited exposure to the real situations. They have limited opportunity to interact with native speakers. This finding is relevant to Labov's (1991:314) view that women are often 'closed' in the home.

\section{d) Sentence Complexity}

Only female test-takers found difficulties in understanding aural long, complex sentence contained in short conversations asked with Deixis questions. Understanding deixis requires recognition of context. They lack of understanding of contextual clues. This finding is in line with Tongshun's (2007) statement that the inference of implicature, for instance, the role and status of interlocutors, setting of conversation and type of speech acts should be worked out through contextual clues. 


\subsubsection{Presupposition Question}

\section{a) Pronunciation}

The male test-takers find it difficulty to understand the sounds of certain words implying pragmatic meanings, while female test-takers did not suffer from the difficulty. This finding is relevant to Larsen-Freeman and Long's (1991) statement that females are superior to males in listening skills.

\section{b) Cultural Value}

Cultural value involves politeness. Politeness is one expression of the cultural aspects of human being. Lack of understanding of politeness markers, for example, may result from limited exposures. Exposure could be an alternative for cultural-awareness raising. Both male test-takers and female test-takers still have to improve the quantity and quality of their exposure. This suggestion is in line with Alagozlu and Buyukozturk's (2009) statement that EFL learners' listening ability could be improved through direct exposure. Therefore, providing broader opportunities for EFL learners to expose to the real situations is a wise effort.

\section{c) Gender}

Male test-taker said that Man's (the second speaker's) voice is easy to understand. It indicates that voice of the same-sex interactants facilitate pragmatic understanding. This finding is consistent with Tannen's (1982) study showing that gender-segregated play patterns in childhood contributes to pragmatic ability. Amin (2003) also states that females' voices on the recordings might be more difficult to understand than male voice. Frankly speaking, in the context of this test item, 'gender' of the speaker has an influence on listening comprehension.

\section{d) Discourse Marker}

In this type of implicature question, male test-takers made errors. They found the meaning of the discourse markers vague. Their failure results from lack of concentration. This situation does not occur to females.

\section{e) Sentence Complexity}

Male test-takers experienced that a complex sentence is difficult to interpret. It needs meaning processing and it takes longer time to understand implicit idea. Similar opinions are expressed by other subjects. Sentence complexity has been commonly accepted as one of the five factors affecting the difficulty of the dialogue items in TOEFL ${ }^{\circledR}$ Listening Comprehension (Susan et.al., 1996). Female test-takers also found the length or complexity of the sentences makes them unable to identify the topics or types of language functions. The second speaker's statement, e.g. Since he broke his glasses, he's had to use a spare pair is complicated when listened. This finding is relevant to one of the strategies for doing Part A Listening section of TOEFL-like. The listeners are suggested to focus on the second speaker in the conversations. 


\section{f) Context}

Female test-takers' failure is due to limited exposure which leads to low understanding of context of the conversations. This finding is in line with Ryder et al.'s (2008) study which shows that children's ability to infer and integrate information in the comprehension of pragmatic meaning was found to be influenced by the available context where the target language is used.

\subsubsection{Reference Question}

\section{a) Pronunciation}

Inability to process speakers' blended sounds makes both male test-takers and female test-takers failed to answer reference question. This finding is relevant to Taguchi's (2007) statement that pragmatic development is not automatically inherent in the process of attaining general language competence. To both sexes, the development of pragmatic knowledge of understanding aural language may not follow the development of the target language itself, although females tend to develop faster than males.

\section{b) Context}

Although context facilitates listeners, in this conversation it proved that the presence of many contexts is misleading. Context, physical or linguistic part of environment around the utterance, facilitates the hearer to interpret the speaker meaning or implicature. It is relevant to Kai-huai's (2008) view that meaning depends on context.

Essentially, inference is an essential way of understanding context and attaining speaker intent in a conversation. Conversational processing is dependent on inferencing. This is in line with MacFarlane's (2006) statement that inferring is a kind of mental processing which integrates language understanding and cognitive processing. Therefore, recognition of metaphoric and other figurative expressions is needed to raise inferential ability.

\section{c) Sentence Complexity}

Interpreting the implicature of a conversation containing long, complex sentences is a hard job. Both male and female test-taker admit that the abstract or implicit topics and irony are difficult to interpret. The topic of conversation with complex sentences is distracting and sometimes abstract. The more abstract the topic, the harder the listener's tasks. This is relevant to Breland et al.'s, (2004) statement that the combination of an abstract topic with an ironic tone may have caused differential performance for those with lower language proficiency.

\subsubsection{Predictable Action Question}

Theoretically, Labov (1991:206) states that women use a higher frequency of the incoming forms. Women are potentially more skilled than men in predicting actions. However, in the 
present study, women failed in answering Predictable Action question. Their failure is due to their unfamiliarity with the context and lack of exposure. This finding is relevant to Alagozlu and Buyukozturk's (2009) view that predicting probable action is important in terms of minimizing lost of information. Empirically, Chen (2009) found that for foreign language learners, lack of exposure inhibits the learners pragmatic awareness. According to Labov (1991:314), women are often 'closed' in the home.

Therefore, it is important for EFL learners to be able to predict probable actions. Predicting is one of the sub-skills of listening comprehension. It is a means of inferencing. One example of inferencing activity is to predict the probable action. An important part of the skill of listening is being able to predict what the speaker is going to say next (Richards, 2007:184; Sadeghi and Nazarbaghi, 2011). Prediction is difficult for various reasons, such as unfamiliarity with intonation, stress, idioms, etc. However, most predictions depend on more obvious choices of vocabulary.

\section{Conclusion}

\subsection{Types of Implicature Question and Male Test-Takers' Causes of Failure}

a) Meaning/Intent question: Pronunciation (Rarely heard blended sounds.), Cultural Value (Don't know much cultural values.), Sentence Complexity (Difficulty to understand content.), Speech Rate/Delivery (Very fast.), Colloquial (Don't have much vocabulary.) and Mishearing (Missing the sound, not concentrated.), b) Inference question: Pronunciation (Don't understand reduced form or chunking.), Sentence Complexity (Difficulty to get the point.), Colloquial (Unfamiliarity with slangs, etc.), Cultural Value (Don't know much culture-related vocabulary.) and Context (Difficulty to determine setting.), c) Deixis question: Pronunciation (Difficulty to understand blended sounds.) and Discourse Marker (Sometimes, Don't understand the discourse marker.), d) Presupposition question: Pronunciation (Difficulty to understand blended sounds.), Discourse Marker (Carelessness.), Gender (Man's voice is easier.), Sentence Complexity (Difficulty to understand long sentences.) and Cultural Value (Don't know cultural values.) and e) Reference question: Pronunciation (Not clear, the sounds are combined.) and Context (Don't understand the context.).

\subsection{Types of Implicature Question and Female Test-Takers' Causes of Failure}

a) Meaning question: Pronunciation (Seldom listen to reduced forms.), Cultural Value (Cultural values are rarely taught.), Sentence Complexity (It takes long time to understand.); Context (Seldom talked with native speakers.), Colloquial (Limited vocabulary.) and Discourse Marker (Sometimes, it is difficult to understand discourse markers.), b) Inference question: Pronunciation (Rarely used and listened to reduced form.), Sentence Complexity (Difficulty to get the topic.), Cultural Value (Don't know cultural values.) and Context (Lack of contact.), c) Deixis question: Pronunciation (Difficulty to chunk); Discourse Marker (Confused with connector.), Cultural Value (Limited schemata.), Sentence Complexity (Difficulty to understand.) and Context (Rarely communicated with foreigners.), d) Presupposition question: Sentence Complexity (It takes long time to recognize the topic.), Cultural Value (Unfamiliarity with cultural values.) and Context (Limited exposure.), e) 
Reference: Pronunciation (Difficulty to chunk.) and Sentence Complexity (It takes long time to listen.), f) Predictable action question: Context (Rarely talked with foreigners.).

\section{Acknowledgment}

I am so grateful to the Directorate General of Higher Education Department of National Education Republic of Indonesia. which sponsored this study. I would like to offer my whole-hearted gratitude to Prof. Dr. Susanto, M.Pd. who was willing to serve as my doctoral dissertation promoter. I am deeply indebted to Suharsono, M.Phil., Ph.D., my friendly Co-promoter. Of course, I want to express my appreciation to two reviewers, Prof. Dr. Agustinus, M.Pd. and Abdul Munir, Ph. D and other examiners, Prof. I Ketut Budayasa, Ph.D., Dr. Oikurema Purwati, M.Appl. and Slamet Setiawan, MA, Ph.D. I want to extend my gratitude to Kamaluddin, Ph. D. and Dr. Sudirman Wilian, M.A. who have been the validators of the Interview Protocol. I am also really indebted to Drs. H. Sirbagus, MA and Amrullah, M.Pd. who spent so much time during the preliminary studies. Many thanks also go to six subjects of the present study. Finally, my deepest thanks are directed to my wife and my sons for their love and motivation. I would love to dedicate this dissertation to them.

\section{References}

Alagozlu, N. and Buyukozturk, S. (2009). Aural pragmatic comprehension. Novitas-ROYAL , 3(2), 83-92.

Amin, K. (2003). The Effect of Speaker's and Listener's Gender on L2 Listening Comprehension. Indian Journal of Applied Linguistics, 9(1), 99-107.

Arifuddin and Susanto. (2012). Gender-based failure to infer implicatures from TOEFL-like listening. International Journal of Learning and Development, 2(6), 62-72. http://dx.doi.org/10.5296/ijld.v2i6.2681.

Arifuddin. (2012). Sex-based short-term memory of vocabulary trained with Pease and Pease's multimodality. International Journal of Human Resources Studies, 2(4), 208-223. http://dx.doi.org/10.5296/ijhrs.v2i4.2730.

Bara, B. G. (2010). Cognitive pragmatics: The mental processes of communication. Cambridge: The MIT Press. http://dx.doi.org/10.7551/mitpress/9780262014113.001.0001.

Barati, L., \& Biria, R. (2011). The impact of first language intonational clue selection on second language comprehension. Open Journal of Modern Linguistics, 1(2), 33-38. http://dx.doi.org/10.4236/ojml.2011.12005.

Black, E. (2006). Pragmatic stylistics. Edinburgh: Edinburgh University Press.

Blight, R. (2002). Classroom procedure for explicit instruction in conversational implicature. Conference Proceeding of JALT 2002 at Shizuoka Japan, 142-148.

Bloomfield, A., Wayland, S.C., Rhoades, E., Blodgett, A., Linck, J., \& Ross, S. (2011). What makes listening difficult? Factors affecting second language listening comprehension. Maryland: CUniversity of Maryland Center for Advanced Study of Language All Rights 
Reserved.

Blume, C. D. (2010). RAP: A reading comprehension strategy for students with learning disabilities. Unpublished Masters Degree Thesis. May 2010. (CThe University of Nebraska-Lincoln.

Boyle, J. P. (1984). Factors affecting listening comprehension. ELT Journal, 38(1), 34-38. http://dx.doi.org/10.1093/elt/38.1.34.

Breland, H., Y-W. Lee, Najarian, M., \& Muraki, E. (2004). Analysis of TOEFL CBT writing prompt difficulty and comparability for different gender groups. TOEFL Research Reports, Report 76 February 2004. Princeton, NJ: ETS.

Brown, G., \& Yule, G. (1983). Teaching the spoken language. Cambridge: Cambridge University Press.

Butt, M.M, Sharif, M.M, Naseer-ud-Din, M., Hussain, I., Khan, F., \&Ayesha, U. (2010). Listening comprehension problems among the students: A case study of three Govt. Boy's higher secondary schools. European Journal of Social Sciences, 18(2), 311-315.

Cedar, P. (2006). Thai and American responses to compliments in English. The Linguistics Journal, 1(2), 6-28.

Chen, Y. (2009). Learner perceptions of instruction in L2 pragmatics. English Language Teaching Journal, 2(4), 154-161.

Cocco, R., \& F. Ervas. (2012). Gender stereotypes and Figurative language comprehension. Hummana. Mente Journal of Philosophical Studies, 22, 43-56.

Cohen, A. D. (2012). Comprehensible pragmatics: Where input and output come together. In M. Pawlak (Ed.), New perspectives on individual differences in language learning and teaching. NY: Springer. http://dx.doi.org/10.1007/978-3-642-20850-8_16

Corbett, J. (2003). An intercultural approaches to English language teaching. Clevedan: Mulitilingual Matters Ltd.

Corsetti, C. R. (2010). Pragmatic competence in the listening paper of the Certificate of Proficiency in English. BELT JOURNAL Porto Alegre, 1(1), 14-25.

Dogancay-Aktuana, S. (2005). Intercultural communication in English language teacher education. ELT Journal Vol. 59, No. 2, 99-107. http://dx.doi.org/10.1093/eltj/cci023.

Dykstra, L. K. (2006). On pragmatic perception: Do learners of Russian perceive the sociocultural weight of the address pronouns? Unpublished Ph.D. Dissertation University of Iowa, Iowa Research Online. USA: University of Iowa.

Eisenstein, M. (1982). A study of social variation in adult second language acquisition. Language Learning, 32, 367-92. http://dx.doi.org/10.1111/j.1467-1770.1982.tb00977.x.

ETS Researchers. (2008). Validity evidence supporting the interpretation and Use of TOEFL iBT scores. ETS, TOEFL iBT Research Series I, 4. 


\section{MInstitute Macrothink $_{\text {Int }}$}

ETS. (1997). TOEFL: Test and score manual. Princeton, New Jersey: ETS.

Farashayian, A., \& Hua, T. K. (2012). On the relationship between pragmatic knowledge and language proficiency among Iranian mle and female undergraduate EFL learners. The Southeast Asian Journal of English Language Studies, 18(1), 33-46.

Fernandez, E. M., \& Cirns, H. S. (2011). Fundamentals of psycholinguistics. UK: Wiley-Blackwell.

Goldkuhl, G. (2004). Meanings of pragmaticism: Ways to conduct information systems research. A paper presented at the 2nd International Conference on Action in Language, Organizations and Information Systems (ALOIS-2004), 17-18 March, 2004, Linköping University, Sweden.

Hinkel, E. (2005). TOEFL test strategies. (3rd ed.). Jakarta: Binarupa Aksara. PMCid: PMC554104

Hua, X., \& Tongshun, W. (2007). Chinese EFL learners pragmatic performance in listening tasks. CELEA Journal, 30(5), 19-25.

Itakura, H. (2001). Conversational dominance and gender. Amsterdam: John Benjamin Publishing Company.

Jiwandono, P. I. (2006). Culture bias in language testing. TEFLIN Journal, 17(1), 81-89.

John, S. F, Lui, M., \& Tannock, R. (2003). Children's story retelling and comprehension using new narrative resource. Canadian Journal of School Psychology, 18(1), 291-113.

Kai-huai, D. U. (2008). Toward a better understanding and manipulation of meaning: A pragmatic perspective. US-China Foreign Language Journal, 6(5), 54.

Kostin, I. (2004). Exploring items characteristics that are related to the difficulty of TOEFL dialogues items. Princeton, NJ: ETS.

Kramsch. (1993). Plastina -teaching culture in literature in the ESL/EFL classroom. Retrieved August 10, 2012, from http://iteslj.org/Lessons/Plastina-CultureInLiterature/

Krashen, S. D. (1982). Principles and practice in second language acquisition. Oxford: Pergamon.

Labov, W. (1991). The interaction of sex and social class in the course of linguistic change. Language Variation and Linguistic Change, 2, 205-251. http://dx.doi.org/10.1017/S0954394500000338.

Lam, W. Y. K. (2007). Raising students' awareness of the features of real-world listening input. In Richards, J.C. and W.A. Renandya (Eds.), Methodology in language teaching: An anthology of current practices (pp. 248-253). Cambridge: Cambridge University Press.

Larsen-Freeman, D., \& M.H. Long. (1991). An introduction to second language research. New York: Longman. 


\section{MlMacrothink}

International Journal of Linguistics

ISSN 1948-5425

2013, Vol. 5, No. 6

Lee, C. (2010). An exploratory study of the interlanguage pragmatic comprehension of young learners of English. Pragmatics, 20(3), 343-373.

Lenarz, M., Sonmez, H., Joseph, G., Buchner, A., \& Lenarz, T. (2012). Effect of gender on the hearing performance of adult cochlear implant patients. The Laringoscope, 122, 1126-1129. http://dx.doi.org/10.1002/lary.23214.

Loukusa, S. (2007). The use of context in pragmatic language comprehension in normally developing children and children with asperger syndrome/high functioning autism: An application of relevance theory. Published Ph.D Dissertation. Oulu, Findland: Oulu University Press.

MacFarlane, J. (2006). Pragmaticism and inferentialism. A paper presented at the Spring 2006 Seminar on Making It Explicit July 11, 2006.

Markovic, I. (2007). Gender difference in children's language. ANNALES, 7(1), 197 - 206.

Matsuoka, Y. (2009). Possible strategies for listening comprehension: Applying the concepts of conversational implicature and adjacency pairs to understand speaker intention in the TOEFL listening section. Accent Asia, 3(2), 27-56.

Mckelvie, B. (2000). The effect of hyper femininity on communication pattern in dating couples. Dissertation Abstract International, 60, 63-75.

Miller, G. S. (2001). Cracking the TOEFL CBT. Princeton's Review. Retrieved May 2, 2011, from http://www.csie.ntu.edu.tw/ b93021/CBTlisteningwz01.pdf

Mulac, S., Bradac, J., \& Gibbons, V. C. (2001). Empirical support for the gender-as-a-culture hypothesis: An intercultural analysis of male/female language differences. Human Communication Research, 27, 121-152. http://dx.doi.org/10.1093/hcr/27.1.121

Nissan, S., DeVincenzi, F., \& Tang, K.L. (1996). An analysis of factors affecting the difficulty of dialogue items in TOEFL ${ }^{\circledR}$ Listening Comprehension. TOEFL Research Report 51. New Jersey: Princeton.

Richards, J. C. (2007). Curriculum development in language teaching. Cambridge: Cambridge University Press.

Richards, J. C., \& Schmidt, R. (2002). Longman dictionary of language teaching \& applied linguistics (3rd ed.). London: Pearson Education.

Romaine, S. (2003). Variation in language and gender. In Holmes, J. and M. Meyerhoff (Eds.), The handbook of language and gender (pp. 98-118). Hong Kong: Blackwell Publishing. http://dx.doi.org/10.1002/9780470756942.ch4

Rubin, J. (1994). A review of second language listening comprehension research. Modern Language Journal, 78(2), 199-221. http://dx.doi.org/10.1111/j.1540-4781.1994.tb02034.x.

Rueda, Y. T. (2006). Developing pragmatic competence in a foreign language. Colombian Applied Linguistics Journal, 8, 169-182. 


\section{Al Macrothink}

International Journal of Linguistics

ISSN 1948-5425

2013, Vol. 5, No. 6

Ryder, N., Leinonen, E., \& Schulz, J. (2008). Cognitive approach to assessing pragmatic language comprehension in children with specific language impairment. Health Care, 43(4), 427-447.

Sadeghi, K., \& Nazarbaghi, S. (2011). The effect of teaching finite state grammar (FSG) on listening comprehension ability of Iranian intermediate EFL learners. International Journal of Academic Research, 3(2), 595-600.

Saukah, A. (2000). The English proficiency of the academics of the teacher training and education institutions. Jurnal Ilmu Pendidikan, Februari 2000, 7(1), 67-76.

Susan, N., Felicia, D., \& Linda, T.K. (1996). An analysis of factors affecting the difficulty of dialogue items in TOEFL ${ }^{\circledR}$ listening comprehension. NY: ETS.

Taguchi, N. (2007). Development of speed and accuracy in pragmatic comprehension in English as a foreign language. TESOL Quarterly, 41(2), 313-338.

Tannen, D. (1982). Ethnic style in male-female conversation. In J. J. Gumperz (Ed.), Language and social identity (pp.217-231). Cambridge: Cambridge University Press.

Thijittang, S., \& Le, T. (2009). Gender differences and apologies in English of Thai learners: Pragmatic and sociolinguistic perspectives. In J. de Bres, J. \& Holmes, M. Marra (Eds.), Proceedings of the 5th Biennieal International Gender and Language Association Conference IGALA 5 (pp. 51-66), held at Victoria University of Wellington, July 2008.

Treiman, R., Clifton, C., Meyer, A.S., \& Wurm, L. H. (2003). Language comprehension and UC DAVIS, University Extension, Intensive English Program. Retrieved May 2, 2012, from http://www.testwise.com/review.html

Widdowson, H. G. (2009). Discourse analysis. Oxford: Oxford University Press.

Wright, S. W., \& S. G. Sukur. (2011). Soal-soal TOEFL®. Yogyakarta: Kalarana Press.

Yates, L. (2010). Pragmatic challenges for second language learners. In Trosborg, A. (Ed.), Pragmatics across languages and cultures (pp. 287-308). Berlin/New York: Walter de Gruyter GmbH \& Co. KG.

Yin, R. K. (2011). Qualitative research from start to finish. New York \& London: The Guilford Press.

Zaidi, J.F. (2010). Gender differences in human brain: An overview. The Open Anatomy, 2, 37-55. http://dx.doi.org/10.2174/1877609401002010037 